\title{
Knowledge of Hand Hygiene and Oral Health Students at Methodist 3
} Private Primary School Medan

\author{
Veronica Angelia $^{1 *}$, Ervina Sofyanti ${ }^{2}$ \\ ${ }^{1}$ Department of Prosthodontics, Faculty of Dentistry, Universitas Sumatera Utara, Medan, \\ Indonesia \\ ${ }^{2}$ Department of Orthodontics, Faculty of Dentistry, Universitas Sumatera Utara, Medan, \\ Indonesia \\ *Email: veronica_angelia@usu.ac.id
}

\begin{abstract}
Aims: The aim of this study was to assess the knowledge among students at private school towards hand hygiene and oral health in Medan, Indonesia. Materials and methods: A cross-sectional study was conducted among 498 students aged 6-12 years of Methodist 3 Primary School in Medan, Indonesia. Knowledge was asssed using hand hygiene and oral health questionnare. Results: $86.95 \%$ of students (426 out of 490) had good knowledge regarding hand hygiene and $78.4 \%$ of students (384 out of 490) had good knowledge regarding oral health. Conclusion: The results of this study indicate that comprehensive hand hygiene and oral health educational programs for primary students are required to achieved this goal.
\end{abstract}

Keyword: primary students, hand hygiene, oral health

\section{INTRODUCTION}

The importance of hand-hygiene and sanitization in preventing highly contagious viral infections to outbreak of the novel coronavirus disease (COVID-19) (Alzyood M et.al, 2020; Bains, 2020). Although direct inhalation of infected respiratory or nasal droplets remains the primary mode of transmission of SARS-CoV-2, hand-hygiene is a very effective method of disease prevention by stopping the indirect transmission (Peng X et al, 2020). The leading health organizations such as World Health Organization and Center for Disease Prevention have endorsed the role of correctly performed hand hygiene as a primary and easy to implement preventive measure for breaking the chain of transmission of the disease (WHO, 2020; CDC, 2020). It is advised to wash hands with soap and water for 40-60 s, and if it is not available, then with an alcohol-based hand rub (ABHR) for at least $20 \mathrm{~s}$ (NCDC, 2020). Unlike the germicidal action of ABHR that involves protein denaturation and cell membrane disruption, surfactant in the soap reduces water tension, lifts soil and microbes, and thus clean them from the skin. Scrubbing with soap and water results in the mechanical removal of microflora (Kampf G et.al 2004; World Health Organization, 2009) In health-care settings, one can see the pictorial presentation of the five moments.

Similar to hand hygiene, ancient literature reports various preparations and methods of oral hygiene maintenance among the Sumerians, the Babylonians, and the Assyrians (Shaklar G, 2017) At present, standard oral hygiene measures consist of thorough cleaning of all surfaces of teeth using a toothbrush with toothpaste, interdental areas, and tongue daily. An interesting article stated that a suitable time of brushing during COVID-19 pandemic maybe just before stepping out and coming home (Wales, 2020). Recommended timing for tooth brushing should not be less than $2 \mathrm{~min}$, and more than 5 min revealed no additional benefit. Toothbrushes should be changed every 3 months or when visibly frayed. If toothbrush is fraying early than 3 months, it means a person is brushing too hard and forcefully. If toothbrush is not fraying even after 3 months, it means the person is not brushing correctly. 
The aim of this study was to assess the knowledge among students at private school towards hand hygiene and oral health in Medan, Indonesia.

\section{MATERIALS AND METHODS}

A cross-sectional study was conducted among 490 students aged 6-12 years of Methodist 3 School in Medan, Indonesia. Ethical clearance was obtained fromthe Ethical Review Committee of Medical Faculty Universitas Sumatera Utara. The student were explained the content and aim of this study. Verbal consent was obtained from 490 students who volunteered to participate. A self administered questionnare containing set of questions regarding hand-hygiene and oralhygiene knowledge was distributed to all participants.

Knowledge was asssed using WHO hand hygiene and oral health questionnare. This proforma of 5 question of hand hygiene and 5 question of oral hygiene include multiple choice and "true" "false" "I dont know."

Inclusion criteria

All students from grade 1-6 primary school willing to participate were included in the study.

Exclusion criteria

Sick students who were not willing to participate were excluded from the study.

Statistical analysis was done by using percentages and proportions. Using excel data sheets.

\section{RESULT}

The study included a total of 490 students out of which 6-7 years old $12 \%(\mathrm{n}=59), 7-8$ years old $12 \%(n=59), 8-9$ years old $16,1 \%(n=79), 9-10$ years old $17,9 \%(n=88), 10-11$ years old $23,6 \%$ $(\mathrm{n}=116), 11-12$ years old $18,4 \%(\mathrm{n}=91)$.

\begin{tabular}{ccccccc}
\hline & \multicolumn{7}{c}{ Age (years old) } \\
\hline True & $\underline{6-7}$ & $\frac{7-8}{54}$ & $\underline{\frac{8-9}{70}}$ & $\underline{9-10}$ & $\underline{10-11}$ & $\underline{11-12}$ \\
False & 3 & 5 & 7 & 3 & 105 & 82 \\
I Don't Know & 0 & 0 & 1 & 2 & 1 & 0 \\
\hline
\end{tabular}

Table 3.1. The number of answers for question 1 (When there is no water, applying hand sanitizer

(Dettol, Antis) to hands and fingers is the same as washing them), answered by Methodist III Medan Primary School students, ranging from 6 to 12 years old.

\begin{tabular}{ccccccc}
\hline & \multicolumn{7}{c}{ Age (years old) } \\
\hline True & $\underline{6-7}$ & $\underline{7-8}$ & $\underline{8-9}$ & $\underline{9-10}$ & $\underline{10-11}$ & $\underline{11-12}$ \\
False & 0 & 1 & 3 & 2 & 2 & 1 \\
I Don't Know & 0 & 58 & 75 & 85 & 114 & 90 \\
\hline
\end{tabular}

Table 3.2. The number of answers for question 2 (Before meals, you don't need to wash your hands with soap, water is sufficient), answered by Methodist III Medan Primary School students, ranging from 6 to 12 years old. 
Veronica Angelia et.al. Knowledge of Hand Hygiene and Oral Health Students at Methodist 3

\begin{tabular}{ccccccc}
\hline & \multicolumn{7}{c}{ Age (years old) } \\
\hline True & $\frac{6-7}{58}$ & $\frac{7-8}{56}$ & $\frac{8-9}{78}$ & $\frac{9-10}{86}$ & $\frac{10-11}{116}$ & $\frac{11-12}{85}$ \\
False & 1 & 2 & 0 & 1 & 0 & 2 \\
I Don't Know & 0 & 1 & 1 & 1 & 0 & 2 \\
\hline
\end{tabular}

Table 3.3. The number of answers for question 3 (Washing your hands with water and soap after meals is a must), answered by Methodist III Medan Primary School students, ranging from 6 to 12 years old.

\begin{tabular}{ccccccc}
\hline & \multicolumn{7}{c}{ Age (years old) } \\
\hline True & $\frac{6-7}{40}$ & $\frac{7-8}{38}$ & $\frac{8-9}{50}$ & $\frac{9-10}{50}$ & $\underline{10-11}$ & $\underline{11-12}$ \\
False & 15 & 16 & 27 & 36 & 46 & 31 \\
I Don't Know & 4 & 5 & 2 & 2 & 7 & 3 \\
\hline
\end{tabular}

Table 3.4. The number of answers for question 4 (One of the causes for COVID-19 is handwashing without soap), answered by Methodist III Medan Primary School students, ranging from 6 to 12 years old.

\begin{tabular}{ccccccc}
\hline & \multicolumn{7}{c}{ Age (years old) } \\
\hline True & $\frac{6-7}{52}$ & $\underline{7-8}$ & $\underline{8-9}$ & $\underline{9-10}$ & $\underline{10-11}$ & $\underline{11-12}$ \\
False & 7 & 13 & 13 & 4 & 101 & 76 \\
I Don't Know & 0 & 0 & 0 & 0 & 0 & 2 \\
\hline
\end{tabular}

Table 3.5. The number of answers for question 5 (The right time to brush your teeth is after breakfast and after dinner), answered by Methodist III Medan Primary School students, ranging from 6 to 12 years old.

\begin{tabular}{ccccccc}
\hline & \multicolumn{7}{c}{ Age (years old) } \\
\hline True & $\frac{6-7}{51}$ & $\frac{7-8}{55}$ & $\frac{8-9}{75}$ & $\frac{9-10}{80}$ & $\underline{10-11}$ & $\underline{11-12}$ \\
False & 5 & 2 & 3 & 3 & 2 & 4 \\
I Don't Know & 3 & 2 & 1 & 4 & 7 & 4 \\
\hline
\end{tabular}

Table 3.6. The number of answers for question 6 (Toothbrush usage is three months maximum and has to be replaced with a new one), answered by Methodist III Medan Primary School students, ranging from 6 to 12 years old.

\begin{tabular}{ccccccc}
\hline & \multicolumn{7}{c}{ Age (years old) } \\
\hline True & $\frac{6-7}{47}$ & $\frac{7-8}{51}$ & $\underline{8-9}$ & $\frac{9-10}{62}$ & $\underline{10-11}$ & $\underline{11-12}$ \\
False & 3 & 3 & 11 & 3 & 6 & 66 \\
I Don't Know & 8 & 5 & 5 & 8 & 15 & 14 \\
\hline
\end{tabular}

Table 3.7. The number of answers for question 7 (The correct toothbrush is soft-bristled and smallheaded), answered by Methodist III Medan Primary School students, ranging from 6 to 12 years old. 
Veronica Angelia et.al. Knowledge of Hand Hygiene and Oral Health Students at Methodist 3

\begin{tabular}{ccccccc}
\hline & \multicolumn{7}{c}{ Age (years old) } \\
\hline True & $\frac{6-7}{40}$ & $\frac{7-8}{27}$ & $\frac{8-9}{52}$ & $\frac{9-10}{52}$ & $\frac{10-11}{75}$ & $\frac{11-12}{64}$ \\
False & 18 & 32 & 27 & 34 & 36 & 27 \\
I Don't Know & 0 & 0 & 0 & 2 & 5 & 0 \\
\hline
\end{tabular}

Table 3.8. The number of answers for question 8 (You only go to the dentist if you have dental problems, e.g. toothache, bleeding gums, misaligned teeth), answered by Methodist III Medan

Primary School students, ranging from 6 to 12 years old.

\begin{tabular}{ccccccc}
\hline & \multicolumn{7}{c}{ Age (years old) } \\
\hline True & $\frac{6-7}{52}$ & $\frac{7-8}{53}$ & $\frac{8-9}{71}$ & $\frac{9-10}{74}$ & $\underline{10-11}$ & $\underline{11-12}$ \\
False & 3 & 4 & 5 & 10 & 12 & 16 \\
I Don't Know & 4 & 1 & 3 & 4 & 9 & 4 \\
\hline
\end{tabular}

Table 3.9. The number of answers for question 9 (Vitamin deficiency can damage teeth and gum), answered by Methodist III Medan Primary School students, ranging from 6 to 12 years old.

\begin{tabular}{ccccccc}
\hline & \multicolumn{7}{c}{ Age (years old) } \\
\hline True & $\frac{6-7}{58}$ & $\frac{7-8}{58}$ & $\frac{8-9}{78}$ & $\frac{9-10}{84}$ & $\underline{10-11}$ & $\frac{11-12}{78}$ \\
False & 1 & 1 & 1 & 1 & 3 & 10 \\
I Don't Know & 0 & 0 & 0 & 2 & 0 & 2 \\
\hline
\end{tabular}

Table 3.10. The number of answers for question 10 (Maintaining oral health is as important as hand hygiene), answered by Methodist III Medan Primary School students, ranging from 6 to 12 years old.

\section{DISCUSSION}

Effectiveness of hand washing in preventing nosocomial infections is still noted among students. Majority of students (91.4\%) agree when there is no water, applying hand sanitizer (Dettol, Antis) to hands and fingers is the same as washing them. Alcohol-based hand sanitizers may be consider as an alternative to soap and requires less time but the risk of poisoning and intoxication and the high cost must be carefully, especially in developing country (Pratinidhi SA, et al 2020).

Almost all students $(98.1 \%$ ) believed that hand washing is important before meals, they need to wash their hands with soap, not only with water. Almost all students $(97.7 \%)$ washing their hands with water and soap after meals. Soap has beenshown to be effective in promoting hygiene habits and preventing and controlling the spread of disease. Hand washing with a generous amount of clean water is effective at reducing the presence of some viruses, but the use of soap (or alternative rubbing agents) is vital to remove contamination from bacteria, parasites, and fungi (Pratinidhi SA, et al 2020).

Student agree (60.6\%) one causes for COVID-19 is hand-washing without soap. Hands are a potential reservoir and vector for various pathological microorganisms. They come in contact with numerous already contaminated animate and inanimate surfaces. Studies have shown that people touch their face approximately 23 times in an hour, which poses a threat for virus transmission through oral, nasal, or conjunctival mucosa (Vivek, 2020).

Student agree the right time to brush your teeth is after breakfast and after dinner $91.8 \%$. At present, standard oral hygiene measures consist of thorough cleaning of all surfaces of teeth using a toothbrush with toothpaste, interdental areas, and tongue daily. An interesting article stated that a 
suitable time of brushing during COVID-19 pandemic maybe just before stepping out and coming home. Recommended timing for tooth brushing should not be less than $2 \mathrm{~min}$, and more than $5 \mathrm{~min}$ revealed no additional benefit (Vivek, 2020).

Majority students $80,8 \%$ agree toothbrush usage is three months maximum and has to be replaced with a new one. Toothbrushes should be changed every 3 months or when visibly frayed. If toothbrush is fraying early than 3 months, it means a person is brushing too hard and forcefully. If toothbrush is not fraying even after 3 months, it means the person is not brushing correctly. The toothbrush is the most common tool for cleaning teeth and comes in contact with microbial dental plaque and saliva. Thus, retaining microbes in the brush after cleaning the teeth may re-contaminate the mouth (Naik R et.al, 2015). Studies show that after a single use for a duration ranging from the $30 \mathrm{~s}$ to $4 \mathrm{~min}$, toothbrushes may become contaminated by various microorganisms such as bacteria, viruses, yeasts, and fungi (Tomar P, 2014). Often the toothbrushes are stored in bathrooms or combined toilet/bathrooms, which are warm and moist, and are an ideal place for the growth of microorganisms (Karibasappa GN et.al, 2011).

Majority student (80.8) agree the use toothbrush with soft-bristled and small-headed. Soft bristles avoids damage to the gums and small brush heads allow easier access to hard-to-reach areas in the oral environment ( $\mathrm{Ng} \mathrm{C}$ et.al, 2020). Disinfection of toothbrushes after use is often neglected practice. It is seen that the majority of people just rinse the brushes with plain water and then dry it to prevent contamination with potential disease-producing bacteria fungi and viruses (Konidala $\mathrm{U}$ et.al, 2011; Frazelle MR et.al, 2012). In a survey-based study conducted (Peker et al, 2015) to assess knowledge of toothbrush hygiene among dental students, $62.6 \%$ of the respondents reported that they did not know about toothbrush disinfection and did not disinfect their toothbrushes. It is advisable to dip the toothbrushes into an antiseptic mouthwash a few minutes after rinsing with water after each use.

Only $35.5 \%$ students go to the dentist if you have dental problems, e.g. toothache, bleeding gums, misaligned teeth; Frequency of visiting dentist is also determined by the parents of childern and dental attitudes displayed by parents too should be made to understand why it is important to take the children for routine dental check-up (Blaggana A, et al, 2016)

Majority (85.9\%) student agree deficiency can damage teeth and gums. Vitamins may be a modifying factor in the progression and healing of the oral diseases and promoting oral and dental health. The use of supplements with several or certain vitamins for people under physiological or pathological conditions that increase the risk of oral and dental diseases could contribute to protect teeth and periodontal tissue (Taqa AA, 2019)

Almost 95.7\% student agree maintaining oral health is as important as hand hygiene. Oral hygiene is an integral part of personal hygiene practices and should not be neglected. Similar to hand hygiene, oral hygiene is essential in reducing infection from the oral cavity, and thus, its transfer to the upper and lower respiratory tract. Although there is no randomized clinical trial, oral hygiene may imply to reduce the morbidity and mortality related to coronavirus disease pandemic potentially.

\section{CONCLUSION}

The results of this study indicate that comprehensive hand hygiene and oral health educational programs for primary students are required to achieved this goal.Thorough tooth brushing for "Two Times For Two Minutes" in a day is an easy key to remember, and is equally essential as $20 \mathrm{~s}$ of hand hygiene in the current COVID-19 pandemic scenario.

\section{ACKNOWLEDGMENTS}

The team of community service expressed their gratitude to the Chancellor of the Universitas Sumatera Utara through the community service institution for the mono year program of the NON PNBP fund of the Universitas Sumatera Utara number 287 / UN5.2.3.2.1 / PPM / 2020. The team also expressed gratitude to the partners for this service activity. 


\section{REFERENCES}

Alzyood M, Jackson D, Aveyard H, Brooke J. COVID-19 reinforces the importance of handwashing. J Clin Nurs 2020. Doi: 10.1111/jocn.15313.

Bains VK. COVID-19 pandemic: Current scenario and our role. Asian J Oral Health Allied Sci 2020;10:1.

Peng X, Xu X, Li Y, Cheng L, Zhou X, Ren B. Transmission routes of 2019-nCoV and controls in dental practice. Int J Oral Sci 2020;12:9.

World Health Organization from: https://www.who.int/gpsc/5may/hand_hygiene_why_ how_and_when_brochure.pdf? [Last accessed on 2020 on September 07].

Centers for Disease Control and Prevention from: https://www.cdc.gov/handhygiene/index.html. [Last accessed on 2020 September 07].

Available from: https://www.ncdc.gov.in/showfile.php?lid=532. [Last accessed on 2020 September 07].

Kampf G, Kramer A. Epidemiologic background of hand hygiene and evaluation of the most important agents for scrubs and rubs. Clin Microbiol Rev 2004;17:863-93.

World Health Organization. WHO Guidelines on Hand Hygiene in Health Care. Geneva: WHO Press; 2009.

Shaklar G, Carranza FA. Introduction: The historical background of periodontology. In: Newman MG, Takei HH, Klokkevold PR, Carranza FA, editors. Newman and Carranza's Clinical Periodontology. 13th ed. St. Louis, Missouri: Elsevier, Saunders; 2017. p. E1. 28.

Available from: https://www.walesonline.co.uk/news/uk-news/brushingteeth-right-time-helps18167539. [Last accessed on 2020 Jun 08].

Pratinidhi SA, et al. Study of knowledge and practices related to handwashing in school going children of a rural community. Int J Contemp Pediatr 2020; 7(1): 24-29.

Vivek. Is oral hygiene as important as hand hygiene during COVID-19 pandemic? AJOHAS 2020; 10(5):1-5.

Naik R, Mujib BR, Telagi N, Anil BS, Spoorthi BR. Contaminated tooth brushes-potential threat to oral and general health. J Family Med Prim Care 2015;4:444-8.

Tomar P, Hongal S, Saxena V, Jain M, Rana K, Ganavadiya R. Evaluating sanitization of toothbrushes using ultra violet rays and $0.2 \%$ chlorhexidine solution: A comparative clinical study. J Basic Clin Pharm 2014;6:12-8.

Karibasappa GN, Nagesh L, Sujatha BK. Assessment of microbial contamination of toothbrush head: An in vitro study. Indian J Dent Res 2011;22:2-5.

$\mathrm{Ng} \mathrm{C}$, Tsoi JKH, Lo ECM, Matinlinna JP. Safety and design aspects of powered toothbrush-a narrative review. Dent J 2020; 8(15): 1-25.

Konidala U, Nuvvula S, Mohapatra A, Nirmala SV. Efficacy of various disinfectants on microbially contaminated toothbrushes due to brushing. Contemp Clin Dent 2011;2:302-7.

Frazelle MR, Munro CL. Toothbrush contamination: A review of the literature. Nurs Res Pract 2012;2012:420630.

Peker I, Akarslan Z, Basman A, Haciosmanoglu N. Knowledge and behavior of dentists in a dental school regarding toothbrush disinfection. Braz Oral Res 2015;29:48.

Blaggana A, et al. Oral health knowledge, attitudes and practice behaviour among secondaryschool children in chandigarh. JCDR 2016; 10(10): 1-6.

Taqa AA. Vitamins and their relations to oral health: a review study. D IJRP 2019; 22(1): 16 